\title{
Simultaneous Cranial and Spinal Subdural Hematoma
}

\section{-Case Report-}

\author{
Satoshi YAMAgUCHI, Kaoru KURISU, Kazunori ARITA, Masaaki TAKEDA, \\ Itaru TANI*, and Osamu ARAKI* \\ Department of Neurosurgery, Hiroshima University Graduate School of Biomedical Sciences, \\ Hiroshima, Hiroshima; *Department of Neurosurgery, Araki Neurosurgical Hospital, \\ Hiroshima, Hiroshima
}

\begin{abstract}
A 59-year-old male presented with spinal subdural hematoma (SDH) with concomitant cranial chronic SDH manifesting as mild paraparesis and numbness in both lower extremities. Magnetic resonance (MR) imaging showed simultaneous occurrence of cranial and spinal SDHs. The patient was treated conservatively because of poor medical condition and mild neurological symptoms, and recovered well within 1 month. Serial follow-up MR imaging revealed spontaneous resolution of both lesions, with signal intensity changes suggesting the degenerative process of subacute hematoma. The spinal hematoma may have migrated from the cranial lesion. Spinal SDH is a potential sequela of chronic SDH in the cranium.
\end{abstract}

Key words: spinal subdural hematoma, chronic subdural hematoma, lumbar spine, migration

\section{Introduction}

Spinal subdural hematoma (SDH) is a rare hemorrhagic disorder which accounts for only $4.1 \%$ of all spinal hematomas. ${ }^{6}$ Spinal SDH may be caused by apparent trauma, spontaneous onset, or iatrogenic maneuvers such as lumbar spinal puncture and/or hemostatic disorders. ${ }^{3)}$ More than 100 cases of spinal SDH have been reported, and magnetic resonance (MR) imaging has increased the incidence of detection. ${ }^{3,10)}$ Simultaneous spinal and cranial SDH is extremely rare, and may be a distinct subgroup, but only 10 cases have been reported. ${ }^{1,5}$, 9-11,14-16,18,19)

Here, we describe another case of spinal SDH with simultaneous cranial chronic SDH.

\section{Case Report}

A 59-year-old male presented with low back pain, numbness, and motor weakness in both legs. He was transferred to our hospital by ambulance. The patient had a history of brainstem infarction, diabetes mellitus, and hypertension, with mild left hemiparesis as a sequela of the stroke. He was treat-

Received January 6, 2005; Accepted June 13, 2005 ed with medication, including oral anti-platelet therapy. He had no history of antecedent head or back injuries, or lumbar spinal puncture. Laboratory examinations eliminated the possibility of thrombocytopenia and coagulopathy. Neurological examination revealed new slight motor weakness and numbness in the lower extremities.

Cranial MR imaging on admission showed a chronic SDH on the left, and a thin hematoma on the surface of the right cerebral hemisphere and posterior fossa. Spinal MR imaging detected a hematoma at the T11-S1 levels. The cranial lesion had two layers, a hyperintense upper layer and an isointense lower layer both relative to the cerebral gray matter, on both $\mathrm{T}_{2}$-weighted and fluid-attenuated inversion recovery MR imaging. The signal intensity of the spinal lesion was similar to that of the lower layer of the cranial lesion (Fig. 1).

The patient was treated conservatively because of his mild neurological symptoms and poor medical condition. The low back pain and mild paraparesis gradually improved and recovered to the former neurological status within 1 month. Follow-up MR imaging obtained on the 13th hospital day revealed enlargement of the hematoma as a hyperintense lesion on both $\mathrm{T}_{1}$ - and $\mathrm{T}_{2}$-weighted images. Axial MR imaging revealed the hematoma was located 

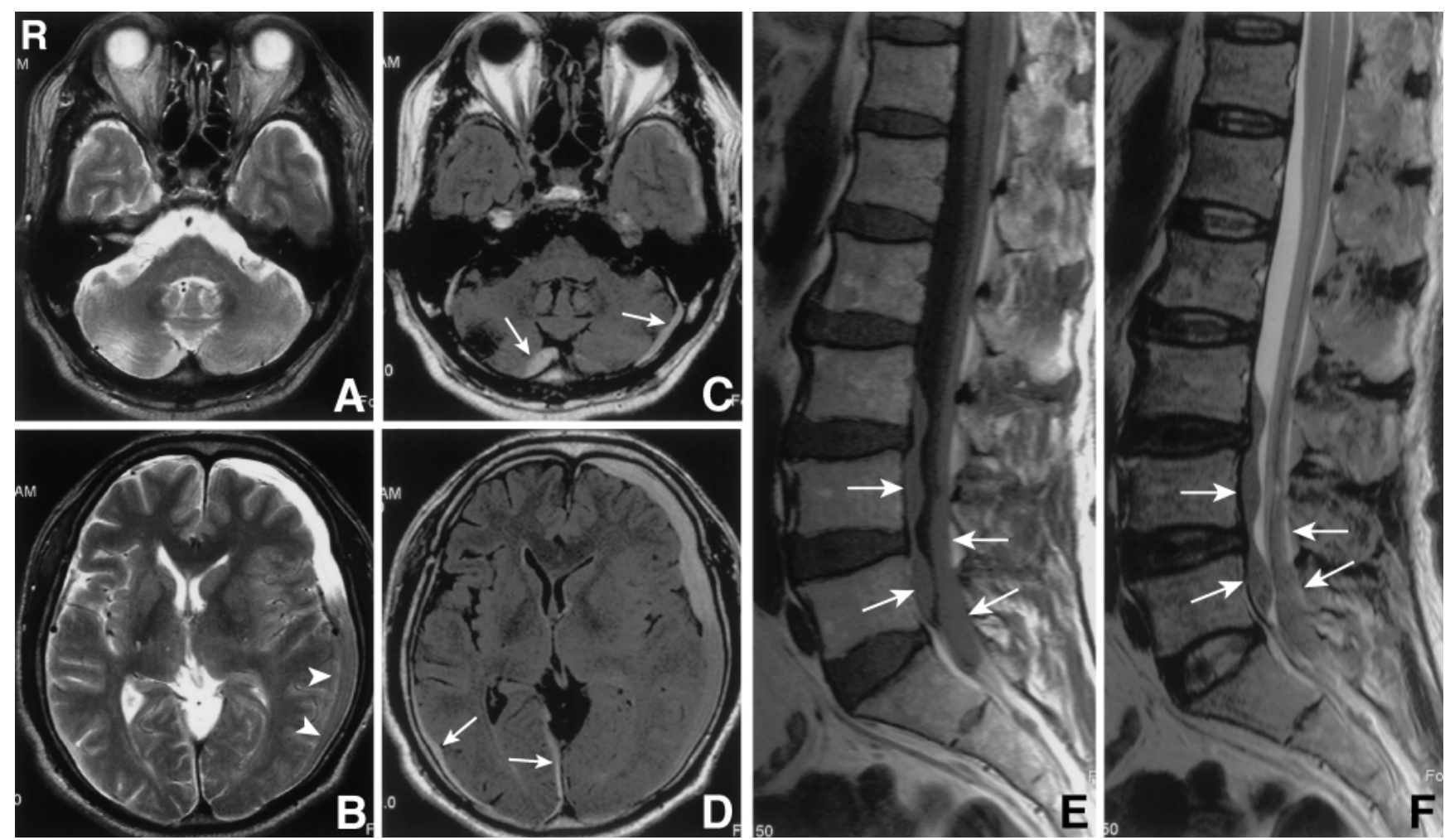

Fig. 1 A, B: Cranial axial $T_{2}$-weighted magnetic resonance (MR) images on admission showing a chronic subdural hematoma in the left hemisphere, with an isointense lower layer (arrowheads) relative to the gray matter. C, D: Fluid-attenuated inversion recovery MR images showing a thin hematoma (arrows) on the right cerebral hemispheric surface and posterior fossa. $E$, F: Lumbar sagittal $T_{1}-(E)$ and $T_{2}$-weighted (F) $M R$ images showing a hematoma (arrows) in the ventral and dorsal spinal canal at the T11-S1 levels, with the signal intensity of the lumbar hematoma similar to that of the lower layer of the cranial hematoma (F).

between the epidural fat and the cerebrospinal fluid (CSF) space. The cauda equina was compressed by the hematoma (Fig. 2). These findings confirmed that the hematoma was localized in the subdural space. Two months after onset, both cranial and spinal SDHs had decreased in volume (Fig. 3A-C). The patient underwent rehabilitation for approximately 3 months and was discharged from the hospital. Final MR imaging obtained 6 months after the onset showed complete resolution of the spinal hematoma (Fig. 3D).

\section{Discussion}

A total of 11 cases of simultaneous occurrence of cranial and spinal SDHs including the present case have been reported (Table 1). ${ }^{1,5,9-11,14-16,18,19)}$ Five patients had acute SDH and six had chronic SDH. Four of 11 patients had undergone CSF diversion, such as ventriculoperitoneal or ventriculoatrial shunting, or external drainage several days or weeks before the onset. MR imaging cannot clearly distinguish between spinal acute and chronic SDH, unlike cranial acute and chronic SDH. Therefore, the spinal lesions in the present case were described as "spinal SDH." All reported spinal SDHs were located below the lower thoracic spine, with the thickest part in the lower lumbar or sacral spinal level. All patients presented with low back or leg pain. Some patients also had paraparesis. Patients with progressive neurological symptoms were treated with surgical intervention. If the symptoms were mild or resolved spontaneously, conservative treatment was chosen. Since good clinical results were obtained by both treatments, conservative therapy can be chosen for a patient with mild symptoms. MR imaging was performed in 10 of 11 cases. All spinal SDHs, except for the present case, appeared as hyperintense on $\mathrm{T}_{1}$-weighted $\mathrm{MR}$ imaging. In our case, the spinal hematoma appeared as isointense on both $\mathrm{T}_{1^{-}}$and 

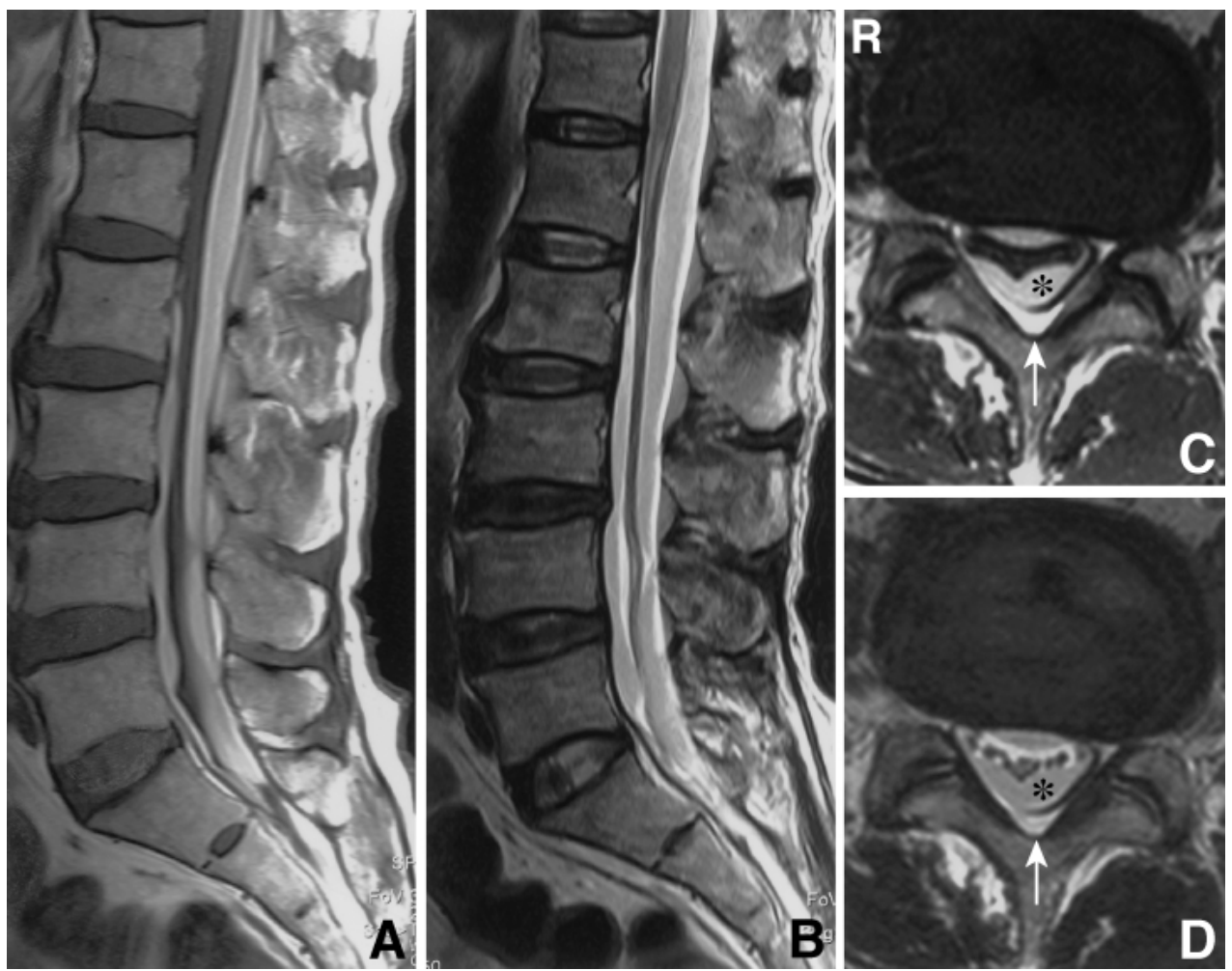

Fig. 2 A, B: Follow-up spinal sagittal magnetic resonance (MR) images obtained on the 13th hospital day showing increased volume of hematoma compared with the initial MR imaging, appearing as hyperintense on both $T_{1^{-}}(A)$ and $T_{2}$-weighted (B) images. $C, D$ : Axial $T_{1^{-}}$(C) and $T_{2}$-weighted (D) MR images at the L-5 level revealing the hematoma (asterisk) located between the epidural fat (arrow) and cerebrospinal fluid space, and the cauda equina compressed by the hematoma.

$\mathrm{T}_{2}$-weighted $\mathrm{MR}$ imaging. Later, the hematoma appeared as hyperintense, first on $\mathrm{T}_{1}$-weighted $\mathrm{MR}$ imaging, and then on $\mathrm{T}_{2}$-weighted $\mathrm{MR}$ imaging. These findings can be interpreted as the degenerative process of the subacute hematoma. ${ }^{4,7)}$

The etiology of the simultaneous occurrence of cranial and spinal SDHs has not been elucidated. The spinal hematoma may be caused by a rupture in the spinal vessels. ${ }^{5,9,12,13)}$ However, the causal relationship between cranial and spinal bleeding is not well documented. Unlike the cranial counterpart, the spinal subdural space lacks the bridging veins as an origin for SDH. ${ }^{9}{ }^{9}$ Spinal hematoma may migrate from the cranial lesion. ${ }^{1,10,11,18,19)}$ Either high or low intracranial pressure has been proposed as a predisposing factor for this migration. Raised intracranial pressure due to brain swelling might displace the hematoma to the skull base or spinal canal. ${ }^{1)}$ Dissection between the dura and arachnoid layer caused by the migrating hematoma may be easier under low CSF pressure resulting from ventriculoperitoneal shunting or CSF drainage. ${ }^{11,15,18,19)}$
Intracranial migration of acute $\mathrm{SDH}$ has been documented in some cases. ${ }^{1,2,8,17)}$ Acute SDH showed gradual sedimentation on the cerebellar tentorial surface and skull base. Spinal SDH with cranial acute SDH could result from this phenomenon. However, whether this mechanism is also applicable to cranial chronic hematoma remains unclear. Chronic SDH has outer and inner membranes in contrast to acute SDH. The contents of the chronic $\mathrm{SDH}$ are unlikely to move freely in the subdural space.

In the present case, the MR imaging findings seem to support the migration theory. The signal intensity and the changes of the spinal hematoma were similar to those of the cranial lesion, suggesting that both hematomas had the same origin. On admission, thin hematoma was present in the retro-cerebellar space, suggesting migrating hematoma in the posterior fossa. The mechanism of movement of the cranial SDH out of the membrane remains unclear. Rebleeding might have occurred in the cranial lesion before the onset, because MR imaging sug- 

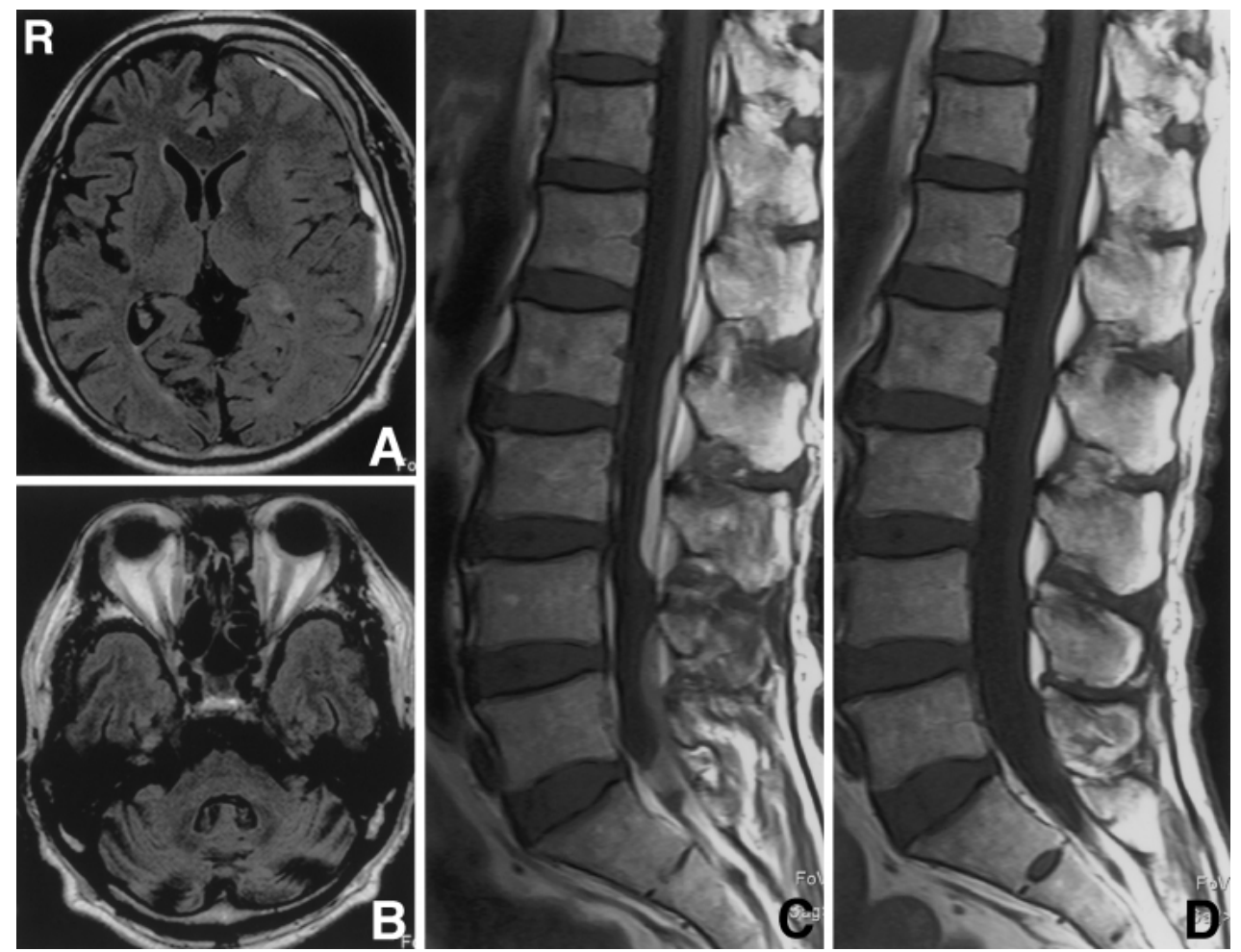

Fig. 3 A-C: Cranial axial fluid-attenuated inversion recovery $(A, B)$ and spinal sagittal $T_{1}$-weighted magnetic resonance (MR) images (C) obtained 2 months after the onset showing both cranial and spinal subdural hematomas had decreased in volume. The cerebral and cerebellar sulci were enlarged, suggesting moderate atrophic change $(A, B)$. D: Final sagittal $T_{1}$-weighted MR image obtained 6 months after the onset showing complete resolution of the spinal hematoma.

Table 1 Summary of the previous and present cases of spinal subdural hematoma (SDH) concomitant with cranial SDH

\begin{tabular}{|c|c|c|c|c|c|c|c|}
\hline Author (Year) & $\begin{array}{l}\text { Age (yrs) } / \\
\text { Sex }\end{array}$ & $\begin{array}{l}\text { Cranial } \\
\text { SDH }\end{array}$ & Level & $\begin{array}{c}\text { MR imaging (T1WI/T2WI) } \\
\text { signal intensity }\end{array}$ & Treatment & Outcome & Predisposing factor \\
\hline Silver and Wilkins $(1991)^{15)}$ & $14 / \mathrm{F}$ & chronic & $\mathrm{T} 12-\mathrm{L} 2$ & $\mathrm{NP} / \mathrm{NP}$ & conservative & GR & VP shunt \\
\hline Wurm et al. $(1996)^{18)}$ & $16 / \mathrm{M}$ & chronic & L3-S2 & high/NM & conservative & GR & VA shunt \\
\hline Shimizu et al. (1999) ${ }^{14)}$ & $52 / \mathrm{F}$ & acute & L4-S2 & high/iso & conservative & GR & \\
\hline Tillich et al. $(1999)^{16)}$ & $54 / \mathrm{M}$ & chronic & L1-S2 & high/high & surgery & GR & \\
\hline Ohta et al. $(2001)^{11)}$ & $10 / \mathrm{F}$ & chronic & L3-S2 & high/high & surgery & GR & VP shunt \\
\hline Yamaguchi et al. $(2003)^{19)}$ & $52 / \mathrm{F}$ & acute & L1-S2 & high/iso & conservative & GR & external CSF drainage \\
\hline Bortolotti et al. $(2004)^{1)}$ & $23 / \mathrm{F}$ & acute & L4-S2 & high/iso & surgery & GR & brain swelling \\
\hline Present case & $59 / \mathrm{M}$ & chronic & $\mathrm{T} 11-\mathrm{S} 1$ & iso/iso & conservative & GR & brain atrophy \\
\hline
\end{tabular}

CSF: cerebrospinal fluid, GR: good recovery, MR: magnetic resonance, NM: not mentioned, NP: not performed, T1WI: $\mathrm{T}_{1}$-weighted, T2WI: $\mathrm{T}_{2}$-weighted, VA: ventriculoatrial, VP: ventriculoperitoneal.

gested that the hematoma was in the subacute phase on admission. Growing hematoma might have torn the membrane. Oral anti-platelet therapy and brain atrophy may have facilitated the rebleeding and migration of the hematoma.

\section{References}

1) Bortolotti C, Wang H, Fraser K, Lanzino G: Subacute spinal subdural hematoma after spontaneous resolution of cranial subdural hematoma: causal relation- 
ship or coincidence? Case report. J Neurosurg 100 (4 Suppl Spine): 372-374, 2004

2) Cohen JE, Eger K, Montero A, Israel Z: Rapid spontaneous resolution of acute subdural hematoma and HIV related cerebral atrophy: case report. Surg Neurol 50: 241-244, 1998

3) Domenicucci M, Ramieri A, Ciappetta P, Delfini R: Nontraumatic acute spinal subdural hematoma: report of five cases and review of the literature. J Neurosurg 91 (1 Suppl): 65-73, 1999

4) Gomori JM, Grossman RI, Hackney DB, Goldberg HI, Zimmerman RA, Bilaniuk LT: Variable appearances of subacute intracranial hematomas on high-field spin-echo MR. AJR Am J Roentgenol 150: 171-178, 1988

5) Hung KS, Lui CC, Wang CH, Wang CJ, Howng SL: Traumatic spinal subdural hematoma with spontaneous resolution. Spine 27: E534-538, 2002

6) Kreppel D, Antoniadis G, Seeling W: Spinal hematoma: a literature survey with meta-analysis of 613 patients. Neurosurg Rev 26: 1-49, 2003

7) Kulkarni AV, Willinsky RA, Gray T, Cusimano MD: Serial magnetic resonance imaging findings for a spontaneously resolving spinal subdural hematoma: case report. Neurosurgery 42: 398-401, 1998

8) Kuroiwa T, Tanabe H, Takatsuka H, Arai M, Sakai N, Nagasawa S, Ohta T: Rapid spontaneous resolution of acute extradural and subdural hematomas. Case report. J Neurosurg 78: 126-128, 1993

9) Leber KA, Pendl G, Kogler S, Kammerhuber F, Ebner F: Simultaneous spinal and intracranial chronic subdural hematoma. Case illustration. J Neurosurg 87: 644,1997

10) Lecouvet FE, Annet L, Duprez TP, Cosnard G, Scordidis V, Malghem J: Uncommon magnetic resonance imaging observation of lumbar subdural hematoma with cranial origin. J Comput Assist Tomogr 27: 530-533, 2003

11) Ohta H, Ottomo M, Nakamura T: [A case of the spinal subdural hematoma formation following ventriculoperitoneal shunting for von Recklinghausen's disease associated with aqueductal stenosis]. No Shinkei Geka 29: 53-57, 2001 (Jpn, with Eng abstract)

12) Rader JP: Chronic spinal subdural hematoma of the spinal cord: Report of a case. N Engl J Med 253: 374-376, 1955

13) Russell NA, Benoid BG: Spinal subdural hematoma. A review. Surg Neurol 20: 133-137, 1983

14) Shimizu S, Tachibana S, Maezawa H, Fujii K, Kan S: Lumbar spinal subdural hematoma following craniotomy - case report. Neurol Med Chir (Tokyo) 39: 299-301, 1999

15) Silver JM, Wilkins RH: Spinal subdural hematoma formation following ventriculoperitoneal shunting for hydrocephalus. Acta Neurochir (Wien) 108: 159-162, 1991

16) Tillich M, Kammerhuber F, Reittner P, Leber KA, Szolar DH: Chronic spinal subdural haematoma associated with intracranial subdural haematoma: CT and MRI. Neuroradiology 41: 137-139, 1999

17) Tsui EY, Fai Ma K, Cheung YK, Chan JH, Yuen MK: Rapid spontaneous resolution and redistribution of acute subdural hematoma in a patient with chronic alcoholism: a case report. Eur J Radiol 36: 53-57, 2000

18) Wurm G, Pogady P, Lungenschmid K, Fischer J: Subdural hemorrhage of the cauda equina. A rare complication of cerebrospinal fluid shunt. Case report. Neurosurg Rev 19: 113-117, 1996

19) Yamaguchi S, Hida K, Akino M, Yano S, Iwasaki Y: Spinal subdural hematoma: a sequela of a ruptured intracranial aneurysm? Surg Neurol 59: 408-412, 2003

Address reprint requests to: S. Yamaguchi, M.D., Department of Neurosurgery, Hiroshima University Graduate School of Biomedical Sciences, 1-2-3 Kasumi, Minami-ku, Hiroshima, Hiroshima 734-8551, Japan.

e-mail: satoya@hiroshima-u.ac.jp 